REVIEW

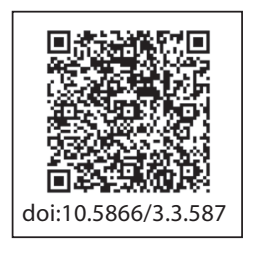

\title{
Role of functional foods in periodontal health and disease
}

\author{
M P Singh ${ }^{1}$, Archana Bhatia
}

Department of Periodontics

Dasmesh Institute of Research and Dental Sciences

Faridkot (Punjab)

Professor and head ${ }^{1}$

Senior lecturer ${ }^{2}$

\section{Article Info}

Received: April 13, 2011

Review Completed: May, 15, 2011

Accepted: June, 17, 2011

Available Online: October, 2011

(c) NAD, 2011 - All rights reserved

\begin{abstract}
:
Probiotics is a live microbial feed supplement which beneficially affects the host animal by improving its intestinal microbial balance whereas Prebiotics are nondigestible substances (dietary fiber)that exert some biological effect on humans by selective stimulation of growth or bioactivity of beneficial microorganisms either present or therapeutically introduced to the intestine. This review focuses on the use of functional foods as preventive and therapeutic products for oral healthcare. Scientific understanding of functional foods and their potential for preventing and treating periodontal conditions is at its infancy, but moving ahead. Therefore, properly controlled, randomized,long term clinical trials are needed using the most promising strains and also testing various methods of application.
\end{abstract}

Key words: Probiotics, Prebiotics, oral health care, functional foods, Periodontal conditions

\section{INTRODUCTION:}

The age -old quote by Hippocrates, 'Let food be thy medicine and medicine be thy food', is certainly the tenet of today. First of all, Greco-Latin civilization considered dietary composition and nutrition style as an essential component of natural medicine. The market for functional foods that promote health beyond providing basic nutrition, is flourishing. The concept of beneficial-for-health microorganisms dates back to the ideas of Nobel Prize Laureate llya Metchnikov in the early years of the $20^{\text {th }}$ century, Working as an Ukranian bacteriologist, laid down the scientific foundation of probiotics. ${ }^{1}$

The term "functional food" describes foodstuffs which, apart from their nutritive value, evidently improve health and well-being of consumers. Functional food can contain probiotics and prebiotics. Within the functional foods, is the small but rapidly expanding arena of probiotics. ${ }^{2}$

"Probiosis" can be defined as the positive effect

Email for correspondence:

dr_mpsingh@yahoo.co.uk; bhatiaarchana16@yahoo.com of consumption of fermented dairy products with cultures of lactic acid bacteria on the equilibrium of intestinal microflora. Recently,side effects of therapy with antibiotics and development of bacteria resistant to them have provoked increasing interest in probiosis. Probiotics and the phenomenon of probiosis were discovered by Mietchnikoff (1908). ${ }^{2}$

\section{PROBIOTICS:}

The term probiotic is derived from the Greek, meaning "for life" is microorganisms proven to exert health -promoting influences in human and animals. "Probiotics" are defined as living organisms in foodstuffs which, when taken at certain levels in nutrition, provide equilibration of the intestinal flora, and hence have a positive effect on the health of the consumer. ${ }^{2}$

Parker defined probiotics as "organisms and substances which contribute to intestinal microbial balance." 3

Fuller redefined probiotics as "A live microbial feed supplement which beneficially affects the host animal by improving its intestinal microbial balance."3 
International Life Science Institute Europe proposed a simple and widely accepted definition of probiotics as-"Viable microbial food supplements which beneficially influence the health". ${ }^{4}$

Saito defined probiotics as "living microorganisms that when administrated in adequate amounts confer health benefits upon the host".1

Probiotics are selected from the strains most beneficial for the host intestinal bacteria, that is bacteria from genera Bifidobacterium, Lactobacillus and yeast(figure I). A Probiotic may be made out of a single bacterial strain or it may be a consortium as well. The advantage of multiple strain preparations is that they are active against a wide range of conditions and in a wider range of animal species. Probiotics can be in powder form, liquid form, gel, paste, granules or available in the form of capsules, sachets, etc (figure II).

\section{History :}

The dietary use of living microorganisms has a long history. Mention of cultured dairy products in the bible and the sacred books of Hinduism. Sacred milks and cultured dairy products such as kefir,koumiss,liben and dahi, were often used therapeutically before the existence of microorganisms was recognized. In 1907, Elie Metchnikoff postulated that consumption of Bulgarian yoghurt promotes good health.In 1950,a probiotics product was used as a drug for the treatment of scour among pigs. Lilley and Stillwell(1965)introduced the term probiotics. Mann and Spoering in 1974 discovered that the fermented yoghurt reduced blood serum cholesterol. In 1984 Hull identified the first probiotic species, the lactobacillus acidophilus. Later in 1991,Holcombh identified bifidobacterium bifidum. WHO in 1994 described the probiotics as next most important in immune defense system following antibiotic resistance.The use of probiotics in antibiotic resistance is termed microbial interference therapy (replacement therapy or bacteriotherapy).

\section{Classification ${ }^{4}$ :}

Probiotics may be yeast,bacteria or moulds, but most commonly bacterial species are predominate.
These are:

- Lactic acid producing bacteria (LAB):Lactobacillus,bifidobacterium,streptococcus.

- Non Lactic acid producing bacterial species : Bacillus, propionibacterium

- Non pathogenic yeasts: Saccharomyces

- Non spore forming and non flagellated rod or coccobacilli

\section{Criteria for the selection of microorganisms":}

- Survival on passing through gastrointestinal tract at low pH and on contact with bile

- Adhesion to intestinal epithelial cells

- Stabilization of the intestinal microflora

- Non-pathogenicity

- Survival in foodstuffs and possibility for production of pharmacopeia preparations

- Fast multiplication,with either permanent or temporary colonization of the gastrointestional tract

- Generic specificity of probiotics

\section{Mechanism of action:}

Probiotics can help prevent and treat disease through several mechanisms(figure III):

- Direct interaction: probiotics interact directly with the disease-causing microbes,making it harder for them to cause the disease.

- Competitive exclusion:Beneficial microbes directly compete with the disease, developing microbes for nutrition or enterocyte adhesion sites.

- Modulation of host immune response:Probiotics interact with and strengthen the immune system and help prevent disease.

\section{Different species used as probiotics(table I):}

Lactobacillus species- help in production of enzymes to digest and metabolize proteins and carbohydrates. They aid in synthesis of vit. $\mathrm{B}$ and vit. $\mathrm{K}$ and facilitates breakdown of bile salts. More than 100 species of L.acidophilus, L.brevis,L.casei, L. rhammous, L.salivaris has been identified. They are usually dispensed in gel,paste,power and liquid forms.

Bifidobacterium species -are strictly anaerobic and predominate the large intestines. These species include metabolization of lactose, generate lactic ions 
from lactic acid and synthesize vitamins. They relieve constipation, alleviate inflammatory bowel disease and prevent DNA damage.

Streptococcus thermophilus and Lactobacillus bulgaricus-these species help in metabolism of lactose,improve lactose intolerance and antimicrobial activity.

\section{Probiotics and HIV4:}

Lin Tao (2008) and his colleagues screened hundreds of bacteria taken from the saliva of volunteers. Results showed that some lactobacillus strains had produced proteins capable of binding a sugar found on HIV envelope,called mannose.One strain secreted abundant mannose-binding protein particles into its surroundings, neutralizing HIV by binding to its sugar coating.

\section{Probiotics in colon cancer prevention:}

Ingestion of probiotics results in different spectrum of fermentation products, including the production of high concentrations of short chain fatty acids. Gut flora,especially after ingestion of resistant starch,includes the chemopreventive enzyme glutathione transferase in the colon.lt results in excretion of byproducts of harmful bacteria such as ammonia,indols, phenols and sulphur components. Together, these factors lead to a reduced load of genotoxic agents in the gut and to an increased production of agents that deactivate toxic components(Reddy 1998,Pierre et al 1999).

\section{Probiotics in calcium absorption:}

Persons with lactose intolerance may probably develop osteoporosis due to decrease consumption of milk containing diet. So,if probiotics are fed to lactose intolerance patients, then milk lactose is hydrolyzed by probiotic strains and favor calcium absorption.

\section{PROBIOTICS AND ORAL HEALTH(table II):}

Ideal vehicles of probiotics installation are yoghurt,milk and cheese.Some of the hypothetical mechanism mechanism of probiotics action in the oral cavity is by:

- Direct interaction in dental plaque

- Involvement in binding of oral micro-organisms to proteins
- Action on plaque formation and on its complex ecosystem by competing and intervening with bacterial attachments

Nase et al showed marked reduction in caries risk with administration of probiotic milk from coded containers for 5 day/week for 7 months. In India, Sporolac,Saccharomyces boulardii and yoghurt(L.bulgaricus +L.thermophilus) are the most commonly used probiotics.Lactobacilli solution is an example of a probiotic, usually given to pediatric patients.

\section{Probiotics and Periodontal health(table III):}

Periodontitis is an infectious disease characterized by inflammatory changes in the tissues surrounding to teeth leading to periodontal attachment loss and alveolar bone destruction. As dental caries has declined, periodontitis has become the most common reason for tooth loss in adults. ${ }^{5}$

It is generally agreed that microorganisms residing in the periodontal pockets are responsible for periodontitis. Approximately 500 taxa inhabit periodontal pockets, which provide a moist, warm, nutritious and anaerobic environment for microbial colonization and multiplication. The abundance and diversity of periodontal pocket microorganisms depend upon several factors, including effectiveness of oral hygiene procedures, pocket depth, flow of gingival crevicular fluid, type of interacting microbes and viruses, transmission rate of microbes from other individuals and the antimicrobial efficacy of the host immune response. ${ }^{6}$

Treatment of periodontal diseases in recent years has moved towards an antibiotics /antimicrobial model of disease management. Probiotics might be a promising area of research in the treatment of periodontitis. For the periodontal treatment,a probiotic bacterium should be able to adhere to and successfully establish itself in the oral biofilm to exert health effects. $T$ he ability of probiotics to adhere to saliva-coated surfaces varies among species and it has been reported that L.rhamnosus and Lactobacillus paracasei strains posses strong binding activity (more than 20\%)(Haukioja et al. 2006). Hillman J D et al 1985, concluded that presence of S.Oralis and S.Uberis provided a good indication of 
periodontium. When these bacteria are absent from sites in the periodontal tissues, those sites are more prone to disease ${ }^{7}$. Ishikava et al.2003, reported that the daily intake of L.salivarius isolated from healthy humans led to a decreased number of black pigmented anaerobic rods. Another study conducted by Koll-Klais et al.2005, they observed speciesspecific antimicrobial activity, with facultative heterofermentative lactobacilli being the strong inhibitors of A.actinomycetemcomitans,P.gingivalis and P.intermedia'

Marcotte et al.2005, have studied a novel means to utilize the beneficial properties of probiotics. They concluded that although lactobacilli as such are not common inhabititants of the gingival sulcus, they can be effectively used in delivering antibodies against P.gingivalis. Mohammad S. et al. 2006, have shown an inverse association between the intake of dairy products and prevalence of periodontitis. ${ }^{8}$ Teughels et al.2007, reported that the subgingival application of a bacterial mixture including Streptococcus sanguis, S.salivarius and Streptococcus mitis after scaling and root planning significantly suppressed the recolonization of Porphyromona gulae(canine P.gingivalis) and P.intermedia in a beagle dog model. This guided approach may provide a valuable addition or alternative to the armamentarium of treatment options for periodontitis. ${ }^{9}$ Recently Haukioja et al. 2008, have shown that probiotic lactobacilli(L.rhamnosus GG, Lactobacillus casei Shirota, L. casei ATCC 11578)may affect the oral ecology by specifically preventing the adherence of other bacteria and by modifying the protein composition of the salivary pellicle. Similarly Yoshihiro Shimazaki et al.2008,concluded that the routine intake of lactic acid foods may have a beneficial effect on periodontal disease. ${ }^{10}$

\section{PREBIOTICS:}

"Prebiotics" are defined as nondigestible substances (dietary fiber)that exert some biological effect on humans by selective stimulation of growth or bioactivity of beneficial microorganisms either present or therapeutically introduced to the intestine $^{2}$ (figure IV).The prebiotic concept was introduced by Gibson and Roberfroid in 1995, several decades after the probiotic model.

Insulin with a low degree of polymerization olgofructosanes,and resistant starch comprise the prebiotics group. Oligofructoses can be found in wheat, onion, garlic, leek, asparagus, Jerusalem artichoke and banana. Mother's milk contains relatively high levels(3-6 g/L) of oligosaccharides. fructooligosaccharides are selectively digested by bifidobacteria and stimulate growth of their colonies. Recently,Klahorst(2000) included polyols such as lactitol, mannitol, sorbitol and xylitol to the prebiotics group.

In order to be effective, a prebiotic must escape digestion in the upper gastrointestinal tract so that it can be released in the lower tract and used by beneficial microorganisms in the colon,mainly bifidobacteria and Lactobacilli. Prebiotic effects depend on solubility, distribution, and branching and length of the chains of the molecules (Rossi M et al. 2005) ${ }^{1}$.Prebiotic fermentation results in the production of increased levels of hydrogen and carbon dioxide and bacterial cell-mass (Cummings J H et al. 2001). ${ }^{1}$

\section{SYNBIOTICS (EUBIOTICS):}

Probiotics and prebiotics simultaneously present in a product are called either synbiotics or eubiotics. Such a combination aids survival of the administered probiotics and facilities its inoculation into the colon. Additionally, the prebiotics induces growth and increases activity of positive endogenic intestinal flora. $^{2}$

\section{CONCLUSION:}

Functional foods are emerging as a fascinating field in oral medicine. This concept prompts a new horizon on the relationship between diet and oral health. Today's new technological era would be the right time to change the way bacteria are treated. At present, effects of functional foods on periodontal health and maintenance are not clear. Functional foods have made their way into oral healthcare and are more likely to be our friend than our enemy. So, further studies are needed to find out the best probiotic / prebiotic and means of their administration. 


\section{BIBILOGRAPHY:}

1. Iva Stamatova and Jukka H Meurman: Probiotics and periodontal disease.Periodontology 2000;51;2009:141-151.

2. Przemyslaw Jan Tomasik and Piotr Tomasik.:Probiotics and prebiotics-Review.Cereal Chemistry 2003;80 (2):113-117.

3. Deepa D,D.S.Mehta: Is the role of probiotics friendly in the treatment of periodontal diseases? JISP Jan-Apr 2009;13:1:30-31.

4. Kedar Saraf,M C Shashikanth,Tulasi Priya,Nishat Sultana,Nallan C S K Chaitanya: .Probiotics-do they have a role in Medicine and Dentistry?-Review article.JAPI Aug 2010;58:488-492.

5. Meyle Jorg, Ammoura Ayham, Hassain Hamid, Bodecker Haso Rolf, Chakraborty Trinad and Domann Eugen: Sustained local delivery of chlorhexidine during initial therapy of chronic periodontitis. Perio 2005;2:117-129.

6. Tazel A,Yucel O,Orbak R,Kara C,Kavrut F,Yagiz H and Sahin $\mathrm{T}$ :The gingival crevicular fluid ciprofloxacin level in subjects with gingivitis and periodontitis, and its effects on clinical parameters. J Periodontol Res 2005;40:395-400.

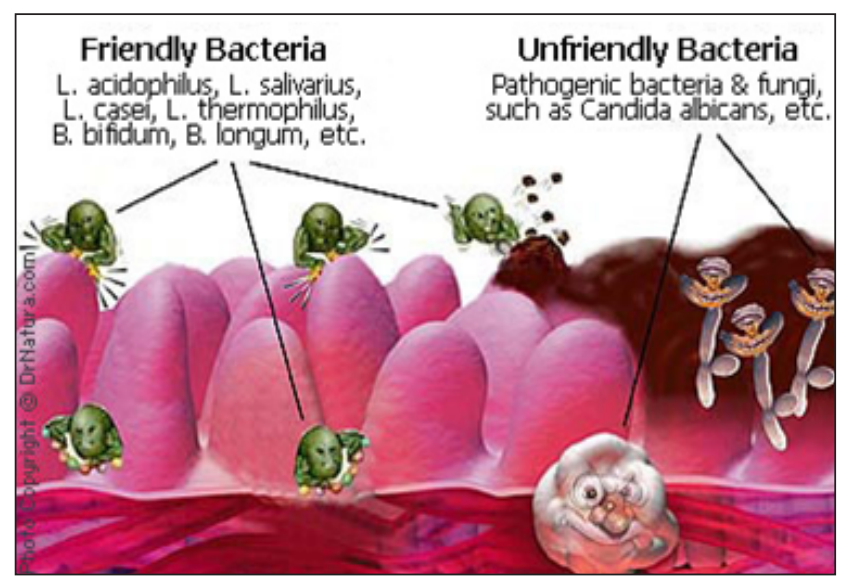

Figure I: Showing beneficial bacterias

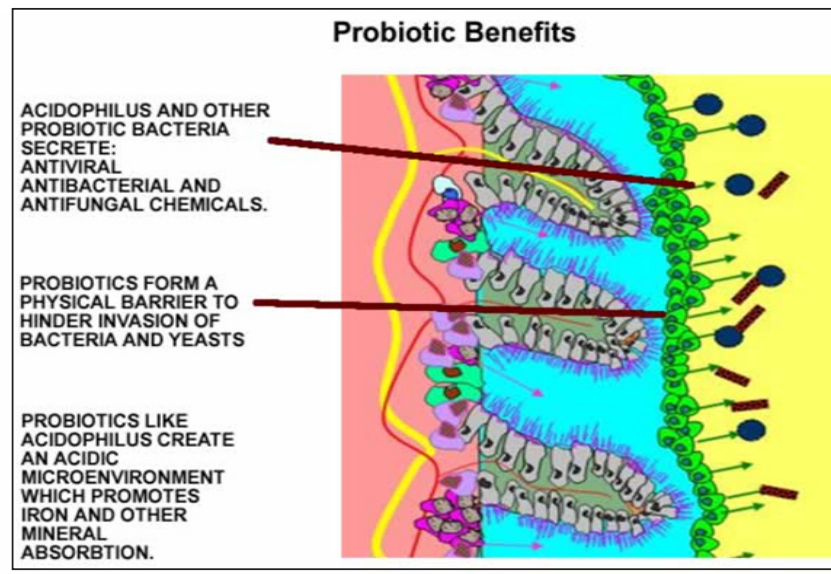

Figure III: Showing mechanism of action of probiotics
7. Hillman J D,Socransky S S,Shivers M.:The relationship between streptococcal species and periodontopathic bacteria in human dental plaque. Arch Oral Biol 1985;30:791-795.

8. Mohammad S.,Al-Zahrani :Increased intake of dairy products is related to lower periodontitis Prevalence.J Periodontol 2006;77:289-294.

9. Teughels W,Newman M G,Coucke W,Haffajee A D,Van Der Mei H C,Haake S K, et al. :Guiding periodontal pocket recolonization:A proof of concept .J Dent. Res 2007;86:1078-1082.

10. Yoshihiro Shimazaki et al:Intake of Dairy products and periodontal disease-The Hisayama study.J Periodontol 2008;79:131-137.

11. Sumit Narang,Ruby Gupta,Anu Narang.:Probiotics in oral health care-a review; International Journal of Scientific and Engineering Research jan 2011; vol 2:issue 1:1-5.

12. Shimauchi H, Mayanagi G,Nakaya S,Minamibuchi M,Ito Y,Yamaki K, et al: Improvement of periodontal condition by probiotics with lactobacillus salivarius WB21:A randomized double-blind,placebo controlled study.J Clin Periodontol 2008;35:897-905.

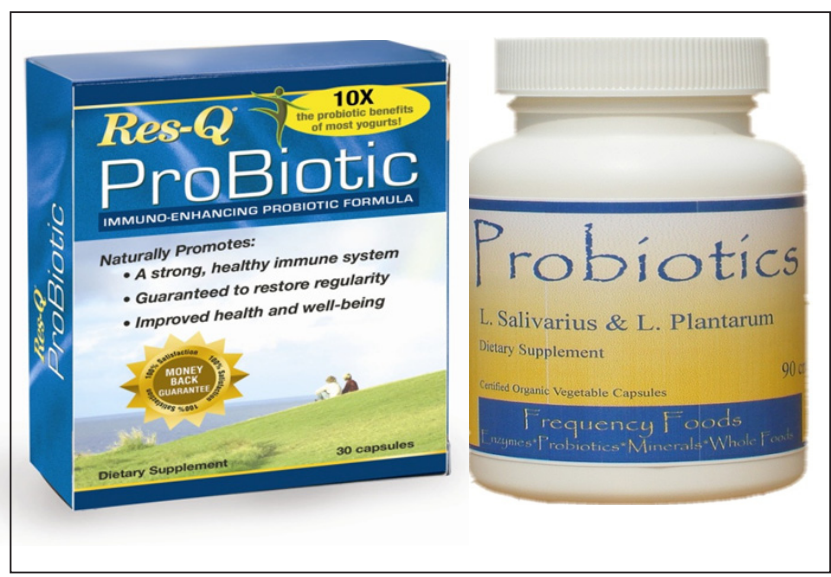

Figure II: Commercially available probiotics

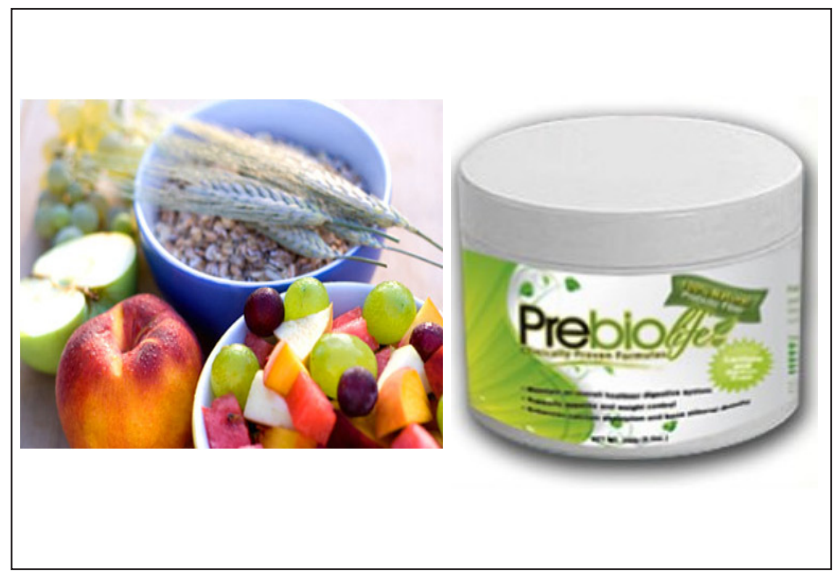

Figure IV: Showing commercially available prebiotics 
Table I: Microorganisms used as probiotics for Humans

\begin{tabular}{|c|c|c|}
\hline Probiotics & Food product & Therapeutic Agent Registered \\
\hline Lactobacillus acidophilus & $\begin{array}{l}\text { Sour milk, } \\
\text { Yoghurt, } \\
\text { Buttermilk, fermented cheese }\end{array}$ & $\begin{array}{l}\text { L.acidophilus, } \\
\text { Lacidofil, Lakeid, } \\
\text { Lakeid forte, Yoghurt }\end{array}$ \\
\hline L. casei & Cheese, Yakult & \\
\hline L.delbrueckii ssp.bulgaricus & Yoghurt & Trilac \\
\hline L.plantarum & Cream, fermented bread & \\
\hline Saccharomyces boulardii, & ......... & Enterol \\
\hline L.reuteri & $\ldots \ldots$ & \\
\hline Bifidobacterium adolescent & $\ldots \ldots$ & \\
\hline B.bifidum & Selected dairy products & Trilac, Lactobif \\
\hline $\begin{array}{l}\text { B.breve,B.infantis, } \\
\text { B.longum,B.lactis }\end{array}$ & $\begin{array}{l}\text { Infants 's milk and probiotic } \\
\text { Cheddar-like }\end{array}$ & Junior Bifidus Nestle \\
\hline L.rhammosus & .........a & L.acidophilus, Lacidofil, \\
\hline
\end{tabular}

Table 2: Probiotic species and their health effect in the oral cavity

\begin{tabular}{|c|c|c|c|}
\hline Probiotic species & Effect & Means of administration & References \\
\hline $\begin{array}{l}\text { L.reuteri ATCC } 55730 \\
\text { L.reuteri ATCC PTA } 5289\end{array}$ & $\begin{array}{l}\text { Reduction in salivary } \\
\text { S.mutans level }\end{array}$ & Lozenge & Caglar et al. 2008 \\
\hline L.reuteri ATCC 55730 & Reduction in salivary S.mutans level & Straw and tablet & Caglar et al. 2006 \\
\hline L.reuteri & Reduction of gingivitis and plaque & Probiotic formulation & Krasse et al.2006 \\
\hline $\begin{array}{l}\text { L.rhamnosus GG, } \\
\text { ATCC } 53103\end{array}$ & $\begin{array}{l}\text { Reduction of the risk of the } \\
\text { highest level of S.mutans }\end{array}$ & Cheese & Ahola et al. 2004 \\
\hline $\begin{array}{l}\text { L.rhamnosus GG, } \\
\text { ATCC } 53103\end{array}$ & $\begin{array}{l}\text { Reduction of the risk of the } \\
\text { highest level of S.mutans }\end{array}$ & Milk & Nase et al.2001 \\
\hline $\begin{array}{l}\text { Bifidobacterium } \\
\text { DN-173 } 010\end{array}$ & $\begin{array}{l}\text { Reduction in salivary } \\
\text { S.mutans level }\end{array}$ & Yoghurt & Caglar et al. 2005 \\
\hline S.salivarius K12 & $\begin{array}{l}\text { Suppressed growth of black pigmented } \\
\text { bacteria in saliva samples and also } \\
\text { of bacteria implicated in halitosis }\end{array}$ & Mouthwash & Burton et al.2006 \\
\hline L.casei 37 & $\begin{array}{l}\text { Extended remission after treatment of } \\
\text { chronic generalized periodontitis }\end{array}$ & Periodontal dressing & Volozhin et al.2004 \\
\hline L.rhamnous GG & $\begin{array}{l}\text { Reduction in growth of Candida } \\
\text { and positive effect on hyposalivation }\end{array}$ & Cheese & Hatakka et al.2007 \\
\hline L.acidophilus LAFTI L10 & Enhanced clearance of C.albica in mice & - & Elahi et al.2005 \\
\hline \multicolumn{4}{|c|}{ Table 3:Probiotic species investigated for treatment of periodontal diseases } \\
\hline Probiotic species & Effect & Means of administration & References \\
\hline L.casei 37 & $\begin{array}{l}\text { Reduction of periopathogens and } \\
\text { extension of remission period }\end{array}$ & Periodontal dressing & Volozhln et al.2004 \\
\hline Probiotic mix & $\begin{array}{l}\text { Normalization of microflora and reduction } \\
\text { of signs of gingivitis and periodontitis }\end{array}$ & $\begin{array}{l}\text { Tablets 'AciLact' and } \\
\text { 'Bifidumbacterin' }\end{array}$ & $\begin{array}{l}\text { Grudianov et } \\
\text { al.2002 }\end{array}$ \\
\hline L.acidophilus & $\begin{array}{l}\text { Improved clinical parameters in periodontitis } \\
\text { patients and shift in local microflora towards } \\
\text { gram positive cocci and lactobacilli }\end{array}$ & Tablet 'Acilact' & $\begin{array}{l}\text { Pozharitskaia } \\
\text { et al.1994 }\end{array}$ \\
\hline L.reuteri & $\begin{array}{l}\text { Reduction of gingivitis and plaque in } \\
\text { patients with gingivitis }\end{array}$ & Study-tailored formula & Krasse et al.2006 \\
\hline $\begin{array}{l}\text { S.sanguinis, } \\
\text { S.salivarius }\end{array}$ & $\begin{array}{l}\text { Delay in subgingival recolonization by } \\
\text { periopathogens }\end{array}$ & $\begin{array}{l}\text { Application of streptococci } \\
\text { after root planing }\end{array}$ & Teughels et al.2007 \\
\hline L.salivarius WB21 & $\begin{array}{l}\text { Improvement in clinical signs of periodontal } \\
\text { disease in smoker and nonsmoker patients }\end{array}$ & $\begin{array}{l}\text { Tablet taken three } \\
\text { times daily }\end{array}$ & $\begin{array}{l}\text { Shimauchi } \\
\text { et al.2008 }\end{array}$ \\
\hline
\end{tabular}

